\title{
sciforum
}

Conference Proceedings Paper

\section{Preparation of pollucite and analcime zeolites as a method to valorize aluminum saline slags}

\author{
Alejandro Jiménez ${ }^{1, *}$, Alexander Misol ${ }^{1}$, Álvaro Morato ${ }^{1}$, Miguel Ángel Vicente ${ }^{1}$, Vicente \\ Rives ${ }^{1}$, Raquel Trujillano ${ }^{1}$, Sophia A. Korili ${ }^{2}$ and Antonio Gil ${ }^{2}$ \\ 1 GIR-QUESCAT, Departamento de Química Inorgánica, Universidad de Salamanca, Plaza de la Merced, \\ S/N, 37008 Salamanca, Spain; alejm@usal.es (A.J.); alex_aspa6@usal.es (A.M.); alvaro_morato@usal.es \\ (Á.M.), mavicente@usal.es (M.Á.V.); vrives@usal.es (V.R.); rakel@usal.es (R.T.) \\ 2 INAMAT^2-Departamento de Ciencias, Edificio de los Acebos, Universidad Pública de Navarra, Campus \\ Arrosadía, 31006 Pamplona, Spain; andoni@unavarra.es (A.G.); sofia.korili@unavarra.es (S.K.) \\ * Correspondence: alejm@usal.es
}

\begin{abstract}
In this work, a valorization procedure is developed for the wastes generated during aluminum recycling, namely, for saline slag. The procedure is divided into two steps: 1) recovery of aluminum from various slag fractions, and $b$ ) the use of recovered aluminum in the synthesis of two zeolites, namely, analcime $\left(\mathrm{NaAlSi}_{2} \mathrm{O}_{6} \cdot \mathrm{H}_{2} \mathrm{O}\right)$ and pollucite $\left(\mathrm{CsAlSi}_{2} \mathrm{O}_{6} \cdot \mathrm{nH}_{2} \mathrm{O}\right)$. Saline slag was ground, sieved $(1 \mathrm{~mm})$, washed and separated into two fractions of different sizes, larger or lower than $0.4 \mathrm{~mm}$. The fraction $<0.4 \mathrm{~mm}$ was treated under reflux conditions with $\mathrm{NaOH}$ or $\mathrm{CsOH}$ solutions of different concentrations. The extraction liquor contained aluminum and alkali metal cations and allowed to obtain the zeolitic materials by hydrothermal synthesis at $20{ }^{\circ} \mathrm{C}$ for 24 hours after adding the necessary amount of $\mathrm{Si}$. These solids were fully characterized. The results of the first step showed that a high percentage of $\mathrm{Al}(\sim 44 \mathrm{wt} . \%)$ in the fraction $<0.4 \mathrm{~mm}$, can be recovered. The results of the second step indicated that crystalline analcime and pollucite zeolites can be hydrothermally synthesized from extraction liquors and a source of $\mathrm{Si}$, the zeolites being the only phases detected by powder X-ray diffraction.
\end{abstract}

Keywords: Saline slag; aluminum recovery; zeolitic materials, analcime, pollucite.

\section{Introduction}

Aluminum properties, such as corrosion resistance, low melting point $\left(660^{\circ} \mathrm{C}\right)$ or low density $\left(2.70 \mathrm{~g} / \mathrm{cm}^{3}\right)$ [1] make it an ideal material for many applications. This element can be recycled and reused without losing its properties. The recycling process requires less energy than primary aluminum production (Bayer and Hall-Héroult processes [2-4]) but other wastes are generated, the most important is the so-called Salt Cake or Saline Slag. It is produced when flux salts (mainly $\mathrm{NaCl}$ and $\mathrm{KCl}$ ) are used for melting aluminum. Salt cake is considered a hazardous waste by in the European Union regulations [5]. Raw saline slag contains various aluminum species (metallic $\mathrm{Al}$, $\mathrm{Al}(\mathrm{OH})_{3}$, different phases of $\mathrm{Al}_{2} \mathrm{O}_{3}$, etc.) forming aggregates of different sizes and can be managed in different ways [2, 6-10].

Analcime (ANA) and Pollucite (POL) are zeolites belonging to the analcime family and their structures are similar [13]. The diameter of channels in pollucite is $2.80 \AA$ [14] while the diameter of $\mathrm{Cs}^{+}$is $3.34 \AA[14,15]$ and $\mathrm{Cs}^{+}$is immobilized inside the pollucite structure, pollucite being a very interesting material for storing ${ }^{137} \mathrm{Cs}$ in a safe way [11-13]. Analcime could be used as an ion exchanger. 
The objective of this work is to use the salt cake in the synthesis of applicable zeolites. Aluminum from the non-metallic fraction of salt cake should be first recovered under reflux conditions. The resulting liquor will be used to synthesize zeolitic materials under hydrothermal conditions. Metallic aluminum could be separated beforehand and submitted to the recycling process. For this reason, metallic $\mathrm{Al}$ will not be used in this work.

\section{Materials and Methods}

Saline slag was supplied by IDALSA, Spain. It was ground in a ball mill, using an alumina jar and alumina balls, and sieved with a $1 \mathrm{~mm}$ light screen. The fraction smaller than $1 \mathrm{~mm}$ was washed with water several times until chloride test was negative, and then dried in an oven at $70{ }^{\circ} \mathrm{C}$ at open air overnight. The chloride free salt cake was sieved with a $0.4 \mathrm{~mm}$ light screen. The fraction with a size between 1 and $0.4 \mathrm{~mm}$ was named intermediate fraction and the fraction less than $0.4 \mathrm{~mm}$ was named small fraction. The recovery of aluminum was evaluated by treating portions of $7.5 \mathrm{~g}$ of the small fraction with $25 \mathrm{~mL}$ of aqueous solutions of $\mathrm{NaOH}$ or $\mathrm{CsOH}$, with concentrations $1,2,3$ or $4 \mathrm{M}$, under reflux conditions, for $2 \mathrm{~h}$, while being magnetically stirred at a speed of $500 \mathrm{rpm}$. The slurries were separated by filtration, using a Büchner funnel and a kitasato flask, and the liquid made up to a final volume of $50 \mathrm{~mL}$. The extraction liquors were named as follows: Name of the reagent $(\mathrm{NaOH}$ or $\mathrm{CsOH}$ ) - concentration of the reagent $(\mathrm{M})$ - time of extraction (h). For instance, $\mathrm{NaOH}-3 \mathrm{M}-2 \mathrm{~h}$, when the extraction was carried out with $3 \mathrm{M} \mathrm{NaOH}$ for $2 \mathrm{~h}$.

Both zeolites were synthesized adapting the method from Garney [16], but using the extraction liquor as the source of aluminum. The amount of extracted $\mathrm{Al}$ was determined beforehand. The source of $\mathrm{Si}$ was $\mathrm{SiO}_{2}$, its stochiometric amount was dissolved in the smallest possible volume of a basic solution of the corresponding alkaline hydroxide, at a $\mathrm{pH}$ close to 13; this excess of alkali warranties the solubility of Si species in the reaction medium. Then, both solutions were mixed and placed in a stainless-steel reactor lined with Teflon and heated at $200^{\circ} \mathrm{C}$ for $24 \mathrm{~h}$. No templates were used. Finally, the solid was recovered by filtration, washed with distilled water until the $\mathrm{pH}$ of the filtrate was lower than 10, de-agglomerated by adding $10 \mathrm{~mL}$ of $10 \%$ ethanol in water and immersed in an ultrasonic bath for $1 \mathrm{~h}$, and then dried at $100{ }^{\circ} \mathrm{C}$ in an oven at open air overnight.

The reagents used in this work were $\mathrm{CsOH} \cdot \mathrm{H}_{2} \mathrm{O}$ (99.5\%, Sigma-Aldrich), $\mathrm{SiO}_{2}$ (high purity grade, $60-100$ mesh, Sigma-Aldrich) and $\mathrm{NaOH}$ (technical grade, Panreac). All reagents were used as received, without any further purification.

The power X-ray diffraction (PXRD) patterns of the solids were recorded in a Siemens D5000 instrument using $\mathrm{Cu}-\mathrm{K} \alpha$ radiation $(\lambda=1.54050 \AA)$, at a scanning rate of $2^{\circ}(2 \theta) / \mathrm{min}$. ICDD database was used to identify the crystalline phases [17]. The $X$-ray microfluorescence spectroscopy (XRF) analyses were carried out using a Bruker M4 model micro-fluorescence spectrometer model (Nucleus Research Platform, University of Salamanca, Spain). The scanning electron microscopy (SEM) analyses were carried out in a Zeiss EVO HD 25 Scanning Electron Microscope, while the Transmission Electron Microscopy (TEM) analyses were performed using a Tecnai Spirit Twin in 120 kV Transmission Electron Microscope, both at the Nucleus Research Platform, University of Salamanca, Spain. The FTIR spectra were recorded in a Perkin-Elmer Spectrum Two instrument with a nominal resolution of $4 \mathrm{~cm}^{-1}$ from 4000 to $400 \mathrm{~cm}^{-1}$, using $\mathrm{KBr}$ (Merck, grade IR spectroscopy) pressed pellets and averaging 20 scans to improve the signal-to-noise ratio. Element chemical analyses for different elements were carried out by ICP-OES in a Yobin Ivon Ultima II apparatus (Nucleus Research Platform, University of Salamanca, Spain). Thermal analyses were performed on a SDT Q600 apparatus (TA instruments) under an oxygen (Air Liquide, 99.999\%) flow of $50 \mathrm{~mL} / \mathrm{min}$ and a temperature heating rate of $2^{\circ} \mathrm{C} / \mathrm{min}$ from room temperature to $900^{\circ} \mathrm{C}$.

\section{Results and Discussion}

Raw salt cake, intermediate and small fractions show a complex chemical composition (Table 1). In addition, other elements such as $\mathrm{V}, \mathrm{Cr}, \mathrm{Mn}, \mathrm{Ni}$ or $\mathrm{Pb}$ are present in the range of $\mathrm{ppm}$. The total $\mathrm{Al}$ content (expressed as oxide) is high, although this is not conclusive for its possible recovery. After washing treatment, sodium was not detected and the amounts of chlorine and potassium drastically 
decreased. Aluminum, expressed as $\mathrm{Al}_{2} \mathrm{O}_{3}$, represented now 70 or $77 \%$ (intermediate or small fraction, respectively) of the sample mass and may be present in many different phases [3, 4].

Table 1. Chemical compositions of the raw salt cake and the fractions with particle size smaller than $1 \mathrm{~mm}$ (expressed as oxides, except for chlorine). Elements with oxide content $\leq 0.2 \%$ are not given.

\begin{tabular}{cccc}
\hline Component & Raw salt cake & Intermediate fraction & Small fraction \\
\hline $\mathrm{Al}_{2} \mathrm{O}_{3}$ & 21.30 & 70.00 & 76.80 \\
$\mathrm{Na}_{2} \mathrm{O}$ & 18.90 & Not detected & Not detected \\
$\mathrm{K} 2$ & 18.90 & 1.10 & 0.45 \\
$\mathrm{MgO}$ & 1.30 & 4.50 & 10.30 \\
$\mathrm{SiO}_{2}$ & 2.20 & 15.00 & 5.30 \\
$\mathrm{CaO}$ & 0.72 & 4.10 & 2.12 \\
$\mathrm{Fe}_{2} \mathrm{O}_{3}$ & 0.70 & 1.40 & 2.00 \\
$\mathrm{CuO}_{\mathrm{SO}}$ & 0.34 & 1.10 & 0.78 \\
$\mathrm{Cl}_{3}$ & 0.24 & 0.29 & 0.50 \\
\hline
\end{tabular}

PXRD (Figure 1, left) showed that in the case of the intermediate fraction, the most intense peaks corresponded to metallic aluminum, while in the small fraction the most intense peaks corresponded to corundum, gibbsite, bohemite, bayerite and spinel. Thus, the small fraction was chosen for the preparation of zeolitic materials because the experimental conditions applied allowed aluminum dissolution as $\left[\mathrm{Al}(\mathrm{OH})_{4}\right]^{-}$anions. Metallic $\mathrm{Al}$ from intermediate fraction could be re-incorporated into the aluminum recycling process.
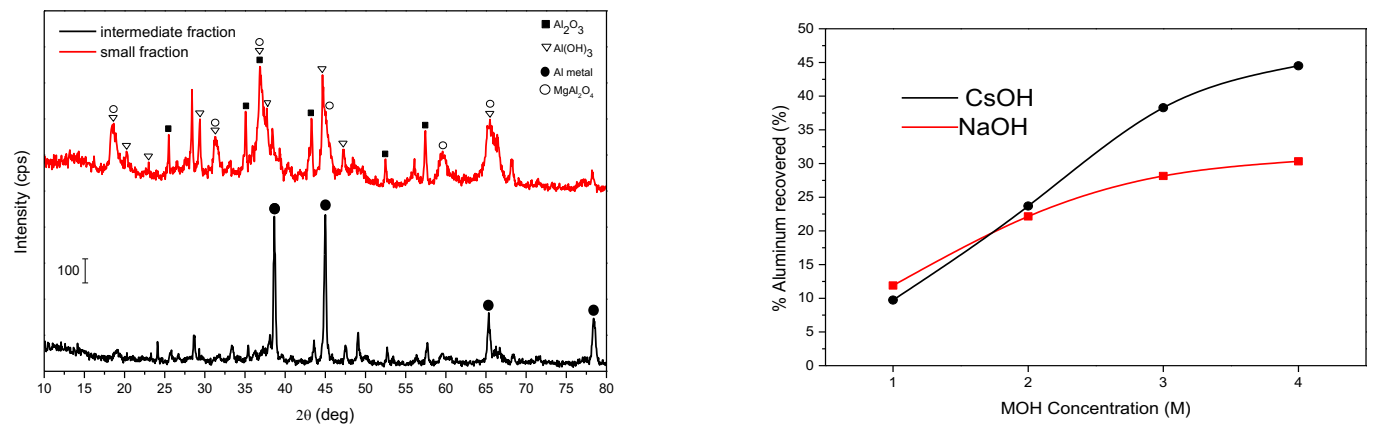

Figure 1. Powder X-ray diffraction patterns of Intermediate and Small fractions (left) and percentage of recovered aluminum using different alkaline hydroxide concentrations (right).

Figure 1 (right) gives information about the percentage of recovered aluminum when using different $\mathrm{NaOH}$ and $\mathrm{CsOH}$ concentrations. A portion of $7.5 \mathrm{~g}$ of small fraction was treated with $25 \mathrm{~mL}$ of 1,2,3 or $4 \mathrm{M} \mathrm{MOH}$ concentrations. The reflux time and the small fraction/dissolution volume ratio were kept constant (reflux time 2 hours and small fraction/dissolution volume was 0.3 ). Under these experimental conditions, an increase in the $\mathrm{MOH}$ concentration produced an increase in the percentage of aluminum recovered. For $\mathrm{MOH}$ concentrations of $1 \mathrm{M}$ and $2 \mathrm{M}$ there were not significant differences in the percentage of aluminum recovered, close to $10 \%$ and $24 \%$ respectively, but for larger $\mathrm{MOH}$ concentrations there were differences in the of aluminum recovered. The extraction liquors $\mathrm{NaOH}-1 \mathrm{M}-2 \mathrm{~h}$ and $\mathrm{CsOH}-1 \mathrm{M}-2 \mathrm{~h}$ were chosen for the synthesis of analcime and pollucite, respectively. The final volume of both liquors was $50 \mathrm{~mL}$ (see their composition in Table 2).

Table 2. Chemical composition (mg/L) of the extraction liquors used in the preparation of zeolitic materials.

\begin{tabular}{cccccc}
\hline Sample & Al & Si & Na & K & Cs \\
\hline CsOH-1M-2h & 5934 & 114 & 545 & 355 & 64081 \\
NaOH-1M-2h & 7159 & 129 & 10230 & 448 & - \\
\hline
\end{tabular}


The PXRD patterns of both synthesized solids (Figure 2, left) show that ANA (ICDD 41-1478) and POL (ICDD 25-194) were prepared from the extraction liquors. Jing et al. [13] concluded that the $\mathrm{Cs} / \mathrm{Al}$ ratio in the starting mixture had no significant effect on the crystallinity. This fact allows to explain that the $\mathrm{Cs} / \mathrm{Al}$ ratio in the extraction liquor is not a limiting parameter for the crystallinity of the final solids. Jing et al. [13] also found that crystalline pollucite was not obtained with a Si/Al molar ratio lower than 1.5 at temperatures lower than $200^{\circ} \mathrm{C}$. Thus, Si/Al ratio of 2 and a curing temperature of $200{ }^{\circ} \mathrm{C}$ were selected for the syntheses. The $\mathrm{Na} / \mathrm{Al}$ ratio has no significant effect influence on the crystallinity of the zeolitic material formed.

The PXRD patters of analcime and pollucite zeolites are very similar to each other. Both belong to the analcime family and have very similar structures; in fact, pollucite-analcime solid solutions with different $\mathrm{Cs} / \mathrm{Na}$ ratios exist in Nature [13]. The ionic diameter of $\mathrm{Cs}^{+}(3.34 \AA)$ [14, 15] is larger than that of $\mathrm{Na}^{+}(2.04 \AA)$ [15]; and $\mathrm{Cs}^{+}$occupies in POL sites which are occupied by $\mathrm{H}_{2} \mathrm{O}$ molecules in ANA.
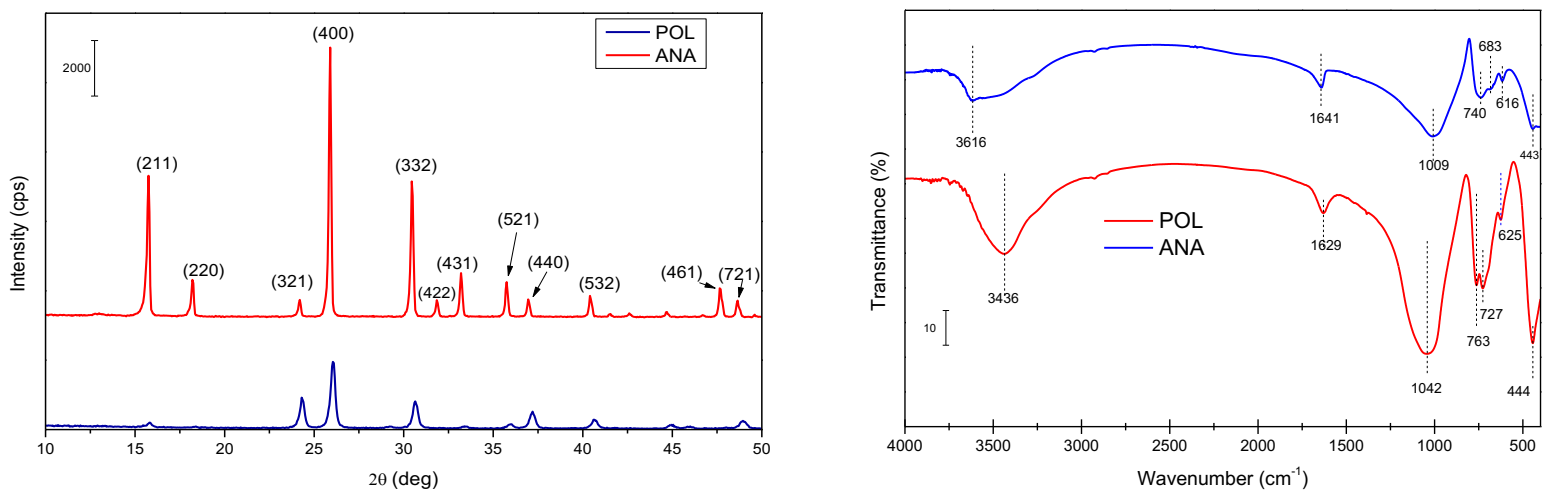

Figure 2. Powder X-ray diffraction patterns (left) and FTIR spectra (right) of ANA and POL.

The FTIR spectra of both zeolites (Fig. 2, right) show few differences. Bands at 1009 and $1042 \mathrm{~cm}^{-}$ ${ }^{1}$ are in both cases assigned to the antisymmetric $\mathrm{T}-\mathrm{O}$ stretching vibrations $(\mathrm{T}=\mathrm{Si}$ or $\mathrm{Al})$, while bands at 763 and $727 \mathrm{~cm}^{-1}$ for POL and $740 \mathrm{~cm}^{-1}$ for ANA are due to the symmetric T-O stretching vibrations. The bands at $625 \mathrm{~cm}^{-1}$ and $616 \mathrm{~cm}^{-1}$ corresponded to the bending vibration of O-T-O units. Bands due to stretching and bending vibrations of water are also recorded.

The main difference between the thermal curves of both zeolites (Figure 3) is their water content. In the case of POL, the water content is around $1.5 \%$ while for ANA it is $8 \%$. This could be explained by the difference in ionic sizes between $\mathrm{Cs}^{+}$and $\mathrm{Na}^{+}$, which implies that $\mathrm{Cs}^{+}$occupies positions that in ANA are occupied by water. The DSC curves show dehydration of POL happens around $200{ }^{\circ} \mathrm{C}$ [13] and for ANA around $308^{\circ} \mathrm{C}$. This fact shows that water in POL is bonded more weakly than in ANA, being removed at a lower temperature.
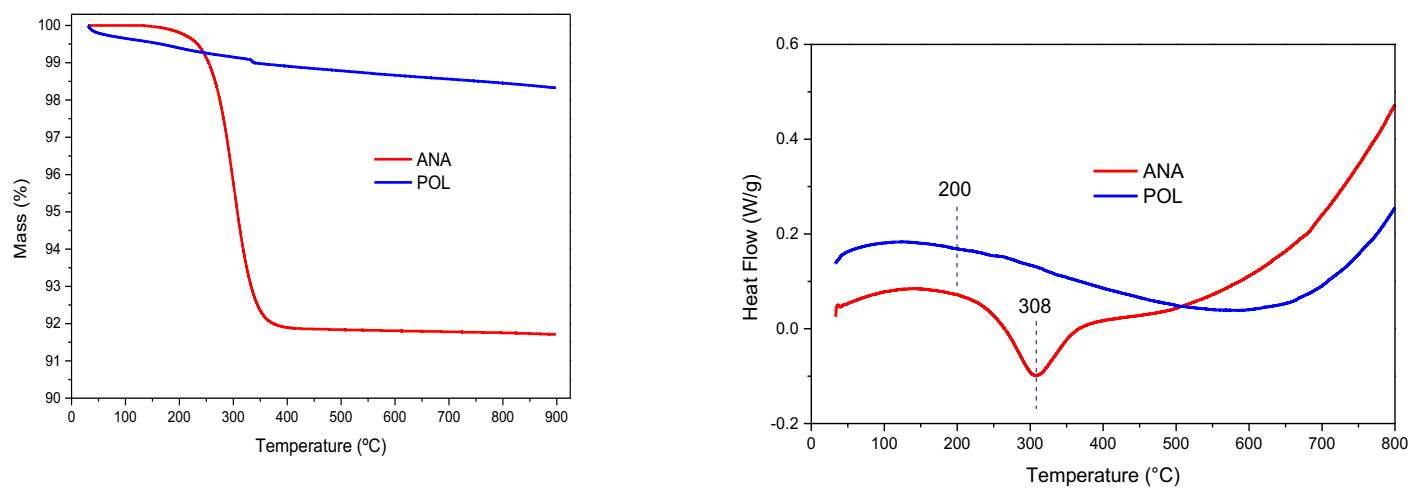

Figure 3. TG (left) and DSC (right) curves of ANA and POL zeolites.

SEM micrographs of ANA (Figure 4 left) show the presence of homogenous and independent 
144

145

146

147

148

149

150

151

152

153

154
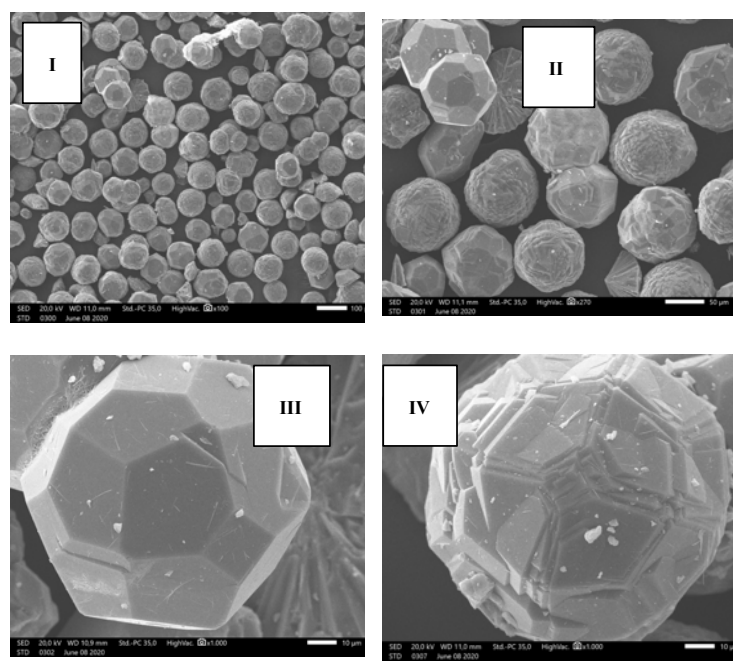

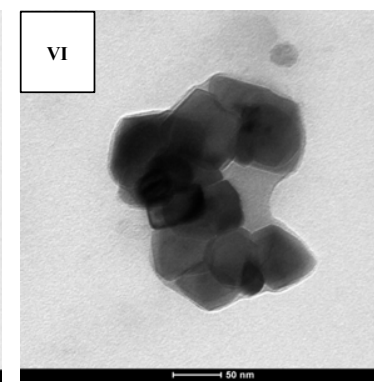

155

156

Figure 4. SEM micrographs (left) and TEM micrographs (right) of ANA.
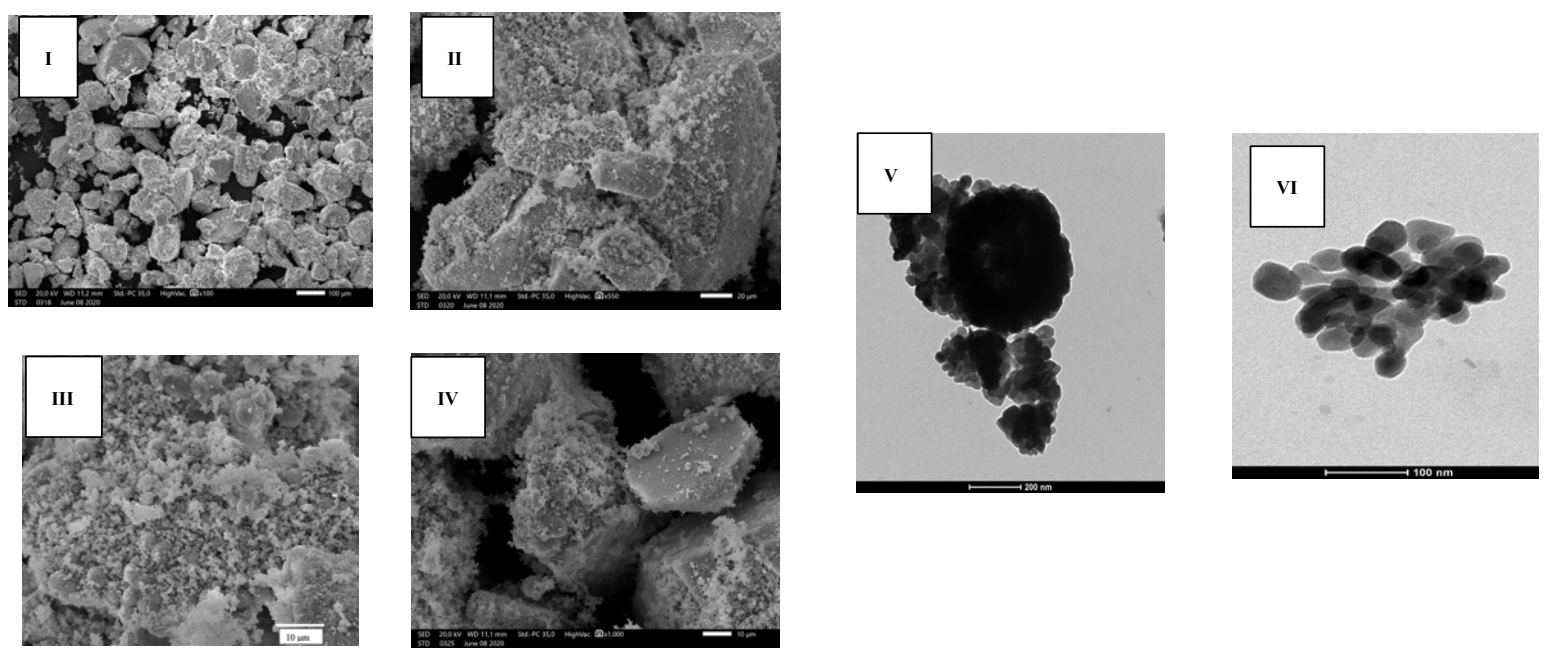

Figure 5. SEM micrographs (left) and TEM micrographs (right) of POL.

\section{8}

Table 3. Chemical composition of the solids prepared (wt\%).

\begin{tabular}{ccccc}
\hline Sample & Al & Si & Na & Cs \\
\hline ANA & 10.87 & 42.36 & 12.22 & - \\
POL & 8.34 & 32.67 & 0.95 & 38.99 \\
\hline
\end{tabular}




\section{Conclusions}

Analcime and pollucite zeolites can be synthesized from aluminum saline slag. First, it is necessary to recover aluminum from the slag under reflux conditions with different alkaline hydroxides. Extraction performance is improved when increasing the hydroxide concentration, being the best extraction at high concentration of $\mathrm{CsOH}$, under reflux for $2 \mathrm{~h}$ and a constant (small fraction/dissolution volume) ratio. The liquor from the extraction is used as a source for $\mathrm{Al}$ in the preparation of the zeolitic materials. Both zeolites are synthesized by the hydrothermal method at $200^{\circ} \mathrm{C}$ for $24 \mathrm{~h}$. Crystallinity and water content is higher for analcime than for pollucite. In both cases, morphological analyses show that spherical particles are formed. The Si/Al ratio is high in both cases, so substitution of $\mathrm{Si}^{4+}$ by $\mathrm{Al}^{3+}$ is small. Therefore, to use analcime as ion exchanger or pollucite for cesium storage; this molar ratio should be smaller, to increase the performance of these materials in these applications.

Author Contributions: Conceptualization, A.J., M.A.V. and V.R.; Methodology, A.J., M.A.V., V.R. and A.G.; Formal analysis, A.J., A. Misol, A. Morato, R.T. and S.A.K.; Investigation, A.J., A. Misol, A. Morato, R.T. and S.A.K.; Resources, M.A.V., V.R., R.T., S.A.K. and A.G.; Writing-original draft preparation, A.J., A. Misol and A. Morato; Writing-review and editing, M.A.V., V.R., R.T., S.A.K. and A.G.; Project administration, M.A.V. and A.G.; Funding acquisition, M.A.V., V.R., R.T., S.A.K. and A.G. All authors have read and agreed to the published version of the manuscript.

Funding: This research was funded by Ministerio de Economía y Competitividad and European Regional Development Fund, grant number MAT2016-78863-C2-R.

Acknowledgments: A.J. thanks Junta de Castilla y León and Sistema Nacional de Garantía Juvenil for a formation contract. A. Misol thanks Junta de Castilla y León and ERDF for a predoctoral contract. A. G. thanks Banco Santander for funding through the Research Intensification Program.

Conflicts of Interest: The authors declare no conflict of interest.

\section{References}

[1] A. Sverdlin, Handbook of Aluminum, E. Totten, United States of America: Marcel Dekker, Inc., 2003.

[2] A. Gil, Management of the salt cake from secondary aluminum fusion processes, Ind. Eng. Chem. Res., vol. 44, no. 23, pp. 8852-8857, 2005, doi: 10.1021/ie050835o.

[3] W. J. Bruckard and J. T. Woodcock, Characterisation and treatment of Australian salt cakes by aqueous leaching, Miner. Eng., vol. 20, no. 15, pp. 1376-1390, 2007, doi: 10.1016/j.mineng.2007.08.020.

[4] W. J. Bruckard and J. T. Woodcock, Recovery of valuable materials from aluminium salt cakes, Int. J. Miner. Process., vol. 93, no. 1, pp. 1-5, 2009, doi: 10.1016/j.minpro.2009.05.002.

[5] Directive 2010/75/EU of the European Parliament and of the Council of 24 November 2010, on industrial emissions (integrated pollution prevention and control). Official Journal of the European Union, 17.12.2010, L 334/17

[6] A. Gil and S. A. Korili, Management of the Salt Cake Generated at Secondary Aluminium Melting Plants, Environ. Manage., no. August 2010, 2010, doi: 10.5772/10104.

[7] A. Gil and S. A. Korili, Management and valorization of aluminum saline slags: Current status and future trends, Chem. Eng. J., vol. 289, pp. 74-84, 2016, doi: 10.1016/j.cej.2015.12.069.

[8] A. Gil, S. Albéniz, and S. A. Korili, Valorization of the saline slags generated during secondary aluminium melting processes as adsorbents for the removal of heavy metal ions from aqueous solutions, Chem. Eng. J., vol. 251, pp. 43-50, 2014, doi: 10.1016/j.cej.2014.04.056.

[9] A. Gil, E. Arrieta, M. A. Vicente, and S. A. Korili, Synthesis and $\mathrm{CO}_{2}$ adsorption properties of hydrotalcitelike compounds prepared from aluminum saline slag wastes, Chem. Eng. J., vol. 334, no. November 2017, pp. 1341-1350, 2018, doi: 10.1016/j.cej.2017.11.100.

[10] A. Gil, E. Arrieta, M. A. Vicente, and S. A. Korili, Application of Industrial Wastes from Chemically Treated Aluminum Saline Slags as Adsorbents, ACS Omega, vol. 3, no. 12, pp. 18275-18284, 2018, doi: 10.1021/acsomega.8b02397.

[11] Y. Chen, Z. Jing, K. Cai, and J. Li, Hydrothermal conversion of Cs-polluted soil into pollucite for Cs immobilization, Chem. Eng. J., vol. 336, no. November 2017, pp. 503-509, 2018, doi: 10.1016/j.cej.2017.11.187.

[12] S. Fu et al., Hydrothermal synthesis of pollucite from metakaolin-based geopolymer for hazardous wastes storage, J. Clean. Prod., vol. 248, p. 119240, 2020, doi: 10.1016/j.jclepro.2019.119240. 
[13] Z. Jing et al., Hydrothermal synthesis of pollucite, analcime and their solid solutions and analysis of their properties, J. Nucl. Mater., vol. 488, pp. 63-69, 2017, doi: 10.1016/j.jnucmat.2017.03.008.

[14] L. Hou, J. Li, and Z. Lu, Hollow-structured pollucite microspheres and the formation mechanism, vol. 282, no. March. Elsevier, 2019.

[15] M. L. Williams, CRC Handbook of Chemistry and Physics, 76th edition, Occup. Environ. Med., vol. 53, no. 7, pp. 504-504, 1996, doi: 10.1136/oem.53.7.504.

[16] B. W. Garney, Verified Syntheses of Zeolitic Materials, Third Revi. Caen: Published on behalf of the Synthesis Commission of the International Zeolite Association, 2016.

[17] ICDD Database. 2020. JCPDS - International Centre for Diffraction Data (ICDD $\left.{ }^{\circledR}\right)$, Newtown Square, Pa, USA.

(C) 2020 by the authors. Submitted for possible open access publication under the terms and conditions of the Creative Commons Attribution (CC BY) license (http://creativecommons.org/licenses/by/4.0/). 